\title{
Development of Flow Type Cesium Removing Device Using Fluorinated Solvent
}

\author{
Motoshi SUZUKI $^{1 *}$, Hideo TAJIMA ${ }^{1 *}$, Aoi KIKUCHI ${ }^{1}$, Youji TAGUCHI ${ }^{2}$, and Shou-ichi NANBA ${ }^{3}$ \\ ${ }^{1}$ Graduate School of Science and Technology, Niigata University, 2-8050 Ikarashi, Niigata 950-2181, Japan \\ ${ }^{2}$ Niigata TLO, 2-8050 Ikarashi, Niigata 950-2181, Japan \\ ${ }^{3}$ Nanba Ltd., 633-1 Mishimashinbo, Nagaoka, 940-2311, Japan
}

\begin{abstract}
In order to simultaneously achieve separation and volume reduction of radioactive cesium in the aqueous solution, we proposed a solvent extraction using a fluorinated solvent which is a nonflammable liquid having a low boiling point and is easy to distill for regeneration. Firstly optimum conditions for single extraction were determined in a batch operation. The extraction experiment was carried out by changing the $\mathrm{pH}$ of $5 \mathrm{mg} / \mathrm{L}$ non-radioactive cesium aqueous solution using bis(2-ethylhexyl)phosphoric acid (D2EHPA) as an extractant. The higher the $\mathrm{pH}$ of the aqueous phase and the D2EHPA concentration, the better the removal rate. The highest removal rate was about $60 \%$ under the $\mathrm{pH}=13$. From the experimental results, the optimum extraction condition was determined as $\mathrm{pH}=13$ and [D2EHPA] $=0.15 \mathrm{~mol} / \mathrm{L}$. Next multiple extraction test was carried out under this condition, and $90 \%$ cesium removal could be achieved in 3 times extraction. Finally, the flow type device using a static mixer for mixing and extracting parts was proposed and then the cesium removal test was performed. The cesium removal performance of this device was equivalent to the batch system.
\end{abstract}

\section{Introduction}

Fukushima accident caused a large amount of cesiumcontaminated water and contaminated soil to which cesium was adsorbed. It is necessary to dispose of them accordingly and to separate and recover radioactive cesium from them.

A general of separating cesium from an aqueous solution is adsorption and solvent extraction. The adsorption method utilizes the fact that an adsorbent having pores close to the ion radius of cesium captures cesium ions. Zeolites are highly selective to cesium and adsorb with high efficiency, but they are not suitable for reuse after adsorption. There is also a method of adsorption using Prussian blue that is selective to cesium, but there is a risk of producing toxic cyanide.

The solvent extraction method is a method of transferring cesium ions in an aqueous solution into an organic phase using an extractant and a diluent. In general, benzene, cyclohexane or the like is used as a diluent. However, such organic solvents have high boiling points and are flammable, and the odor and drainage treatment costs are high, so there is a problem from the viewpoint of recovery and reuse. After extraction, moreover, to reuse the organic solvent, it is common to perform back extraction from the organic phase with acid. As a result, an acidic cesium aqueous solution will be generated again.
To solve the problem we proposed solvent extraction using fluorinated solvents to simultaneously achieve separation and volume reduction of radioactive cesium in aqueous solution. Fluorinated solvents are nonflammable and have a low boiling point, and thus are easy to be regenerated by distillation. Because of low solubility in water and higher density than that of water, phase separation is quick. The cesium can be concentrated and recovered by distilling the organic phase after extraction, and the solvent can be reused.

Hydrochlorofluorocarbon (HCFC-225) is the most common liquid fluorinated solvent at ordinary temperature. However, because it has a chlorine atom in the molecule, it is regarded as a regulated substance by the Montreal Protocol. For this reason, hydrofluoroether (HFE-347-pc-f) is being developed as one of the alternatives. There is no ozone depleting effect because of no chlorine atoms in the molecule, and the physical properties are similar to HCFC-225. Two fluorinated solvents were used in this study. The chemical formula and representative physical properties are shown in Table 1

The purpose of this research is to determine the optimum conditions for cesium extraction with fluorinated solvents, and to perform multiple extractions to improve the removal rate. Based on the results, a flow type device was prepared and tested. The extraction operation was carried out under different conditions, and

* Corresponding Authors: f19b056h@mail.cc.niigata-u.ac.jp (M. Suzuki), h_tajima@eng.niigata-u.ac.jp (H. Tajima) 
the cesium removal rate from the aqueous phase was calculated.

Table 1. Physical properties of fluorinated solvents

\begin{tabular}{ccc}
\hline & $\mathrm{HCFC}-225$ & HFE-347-pc-f \\
\hline Chemical formula & $\begin{array}{c}\mathrm{CF}_{3} \mathrm{CF}_{2} \mathrm{CHCl}_{2} / \\
\mathrm{CClF}_{2} \mathrm{CF}_{2} \mathrm{CHClF} \\
(\text { mixture) }\end{array}$ & $\mathrm{CHF}_{2} \mathrm{CF}_{2} \mathrm{OCH}_{2} \mathrm{CF}_{3}$ \\
Boiling points $\left[{ }^{\circ} \mathrm{C}\right]$ & 54 & 56 \\
Density $\left[\mathrm{g} / \mathrm{cm}^{3}\right]$ & 1.55 & 1.474 \\
Viscosity $[\mathrm{mPa} \cdot \mathrm{s}]$ & 0.59 & 0.65 \\
Solubility in water & 0.033 & 0.07 \\
{$\left[/ 100 \mathrm{~g} \mathrm{H} \mathrm{H}_{2} \mathrm{O}\right]$} & & \\
\hline
\end{tabular}

\section{Experimental}

\subsection{Material}

$5 \mathrm{mg} / \mathrm{L}$ cesium aqueous solution was prepared using a cesium standard solution $(1000 \mathrm{mg} / \mathrm{L}$ cesium chloride aqueous solution, Wako Pure Chemical Industries, Ltd., Osaka, Japan). The extractant was bis(2ethylhexyl)phosphoric acid (D2EHPA, >95\%, Tokyo Chemical Industry Co. Ltd., Tokyo, Japan), and Cyclohexane ( $>98.0 \%$, Wako Pure Chemical Industries, Ltd., Osaka, Japan) and fluorinated solvents HCFC-225 (Asahiklin AK-225, Asahi Glass Co. Ltd., Tokyo, Japan) and HFE-347-pc-f (Asahiklin AE-3000, Asahi Glass Co. Ltd., Tokyo, Japan) were used as extraction solvents. The extractant and solvents were used without further purification. The initial $\mathrm{pH}$ in the aqueous phase was adjusted using $5 \mathrm{~mol} / \mathrm{L}$ sodium hydroxide aqueous solution (Wako Pure Chemical Industries, Ltd., Osaka, Japan).

\subsection{Extraction}

\subsubsection{Equilibrium experiment}

All experiments were performed at $298 \mathrm{~K} .20 \mathrm{~mL}$ of the aqueous solution was added to $20 \mathrm{~mL}$ of organic solvent with D2EHPA. The sample was stirred at $1200 \mathrm{rpm}$ for 24 hours using a magnetic stirrer. Thereafter, the cesium concentration of the aqueous phase was measured with an atomic absorption spectrometer (Shimadzu AA-7000).

\subsubsection{Flow type device}

A flow type device as shown in Figure 1 was designed and prepared. The static mixer was used for the mixing and extraction part. Static mixers have no moving parts and can mix even highly viscous fluids and two-phase that have different densities. Cesium aqueous solution and D2EHPA contained fluorinated solvent were supplied using a tube pump (masterflex 7520-40, Yamato Scientific Co. Ltd, Tokyo, Japan) to a static mixer (length: $10 \mathrm{~cm}$, internal diameter: $5 \mathrm{~mm}$, volume of mixing section: $1.77 \mathrm{~cm}^{3}$ ) at Aqueous/Organic solution ratio $=1$. Outlet mixed fluid was collected into the settler. After phase separation by sedimentation, the cesium concentration of the aqueous phase was measured.

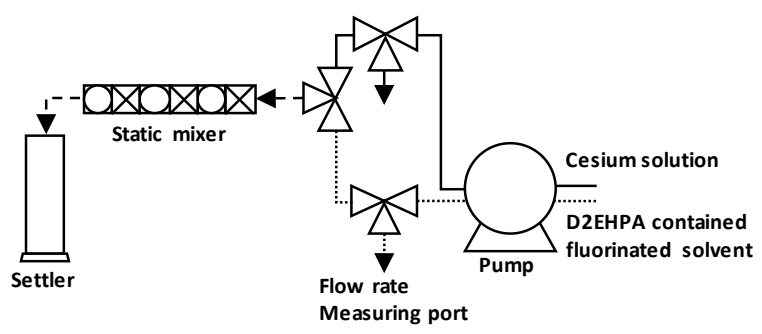

Figure 1. Apparatus for flow type device

\subsection{Analysis}

The removal rate of cesium ions in aqueous solution was calculated by the material balance equation.

$$
\eta=\left\{\left(C_{\mathrm{i}, \mathrm{aq}}-C_{\mathrm{f}, \mathrm{aq}}\right) / C_{\mathrm{i}, \mathrm{aq}}\right\} \cdot 100[\%]
$$

where $C_{\mathrm{i}, \mathrm{aq}}[\mathrm{mg} / \mathrm{L}]$ and $C_{\mathrm{f}, \mathrm{aq}}[\mathrm{mg} / \mathrm{L}]$ are the cesium concentration in aqueous solution before and after extraction.

In the multiple extraction experiment in Section 3.1 .3 , the overall cesium removal rate from the initial cesium concentration $C_{0, \text { aq }}[\mathrm{mg} / \mathrm{L}]$ was calculated.

$$
\eta_{o v}=\left\{\left(C_{0, \mathrm{aq}}-C_{\mathrm{f}, \mathrm{aq}}\right) / C_{0, \mathrm{aq}}\right\} \cdot 100[\%]
$$

\section{Result and Discussion}

\subsection{Equilibrium experiment}

\subsubsection{Effect of initial $\mathrm{pH}$}

The effect of the initial $\mathrm{pH}$ of the aqueous phase on the extraction rate was investigated using HCFC-225. The cesium removal rate with various D2EHPA concentrations at different $\mathrm{pH}$ is shown in Figure 2. The higher the $\mathrm{pH}$ and D2EHPA concentration, the higher the cesium removal rate. The highest removal rate was shown at the initial $\mathrm{pH}=13$. The general reaction of D2EHPA can be represented by the following equation (Mansur et al., 2002; Jang et al., 2017).

$$
\mathrm{M}^{m+}{ }_{\text {aq }}+n(\mathrm{RH})_{2 \text { org }} \leftrightarrow \mathrm{MR}_{m}(\mathrm{RH})_{2 n-m \text { org }}+m \mathrm{H}^{+}{ }_{\mathrm{aq}}
$$

Here, RH is D2EHPA, $m$ is a metal valence number, and $n$ is a stoichiometric coefficient. From the Eq. (3), extraction of metal ions to the organic phase is promoted as the D2EHPA concentration is high or the proton concentration is low. As the reaction proceeds, the concentration of protons in the aqueous phase increases, so the $\mathrm{pH}$ decreases.

In this study, the $\mathrm{pH}$ of the cesium aqueous solution was adjusted using a sodium hydroxide aqueous solution. Because cesium ions and sodium ions coexist in the aqueous phase, D2EHPA extracted not only cesium ions but also sodium ions (Ibrahim, 2010). 


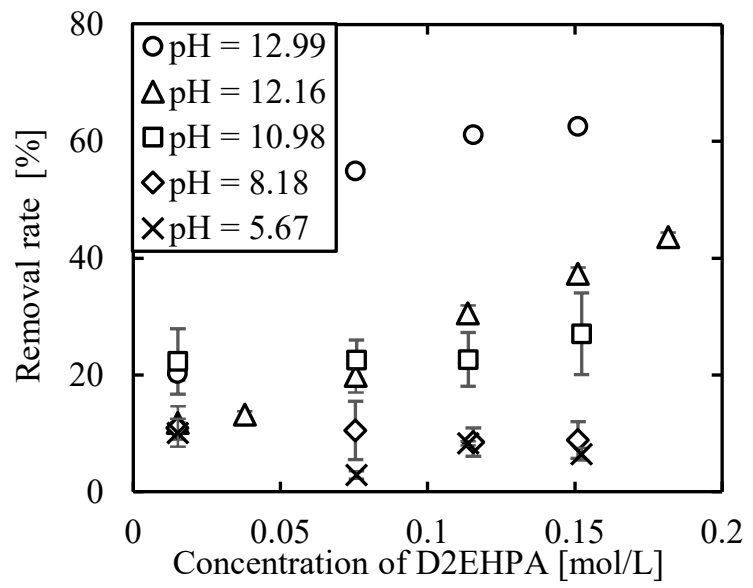

Figure 2. Effect of D2EHPA concentration on cesium removal rate at different $\mathrm{pH}$

The viscosity of the aqueous solution and the solvent increased and gel formation was observed under conditions where the initial $\mathrm{pH}$ was above 11. This is considered to be due to reverse micelle formation by the extraction complex of D2EHPA and metal ions. The tendency of D2EHPA to form gels at a high loading of the organic phase by metal ions is a well known phenomenon (Antico et al., 1996). The present results are in agreement with these findings. Although the viscosity increase of the sample is observed, the Cs removal at the condition of $\mathrm{pH}=13$ is higher than of $\mathrm{pH}=11$.

From these results, the operation conditions for extraction were determined to be $\mathrm{pH}=13$ and [D2EHPA] $=0.15 \mathrm{~mol} / \mathrm{L}$, and the subsequent experiments were performed.

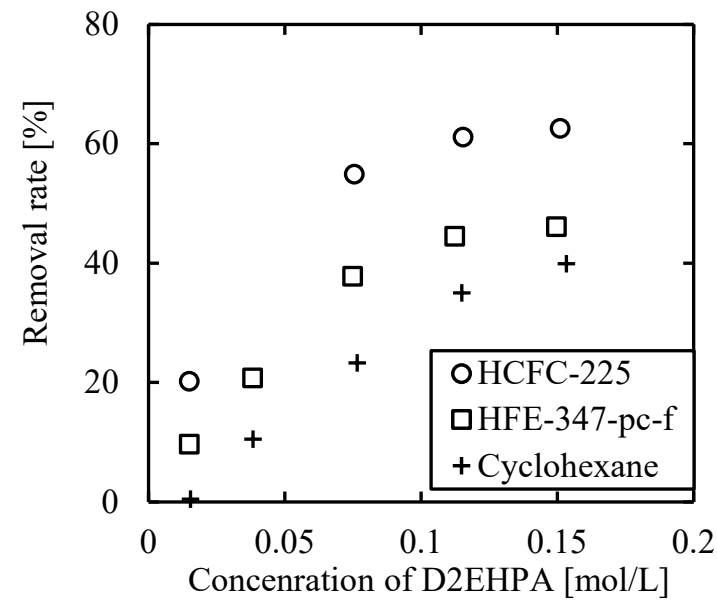

Figure 3. Cesium removal rate in aqueous solution by extraction with various solvents. (initial $\mathrm{pH}$ : 12.713.1)

\subsubsection{Effect of different solvents}

The influence of the solvent was investigated under the initial $\mathrm{pH}=13$ of the aqueous phase. The removal rate in a fluorinated solvent was higher than that in cyclohexane as a conventional solvent (Figure 3 ). In addition, phase separation was completed in a shorter time in the case of the fluorinated solvent compared to cyclohexane. This is because the density of the fluorinated solvent is approximately $1.5 \mathrm{~g} / \mathrm{cm}^{3}$. The use of a fluorinated solvent is appropriate to cesium ion removal.

\subsubsection{Multiple-extraction test}

Three-stage extractions were carried out under the extraction conditions determined in Section 3.1.1. The first stage was carried out using $75 \mathrm{~mL}$ of the D2EHPAcontaining fluorinated solvent and $75 \mathrm{~mL}$ of an aqueous cesium solution in a $200 \mathrm{~mL}$ Erlenmeyer flask. After that, $50 \mathrm{~mL}$ of the aqueous solution was separated, and $50 \mathrm{~mL}$ of a fresh D2EHPA-containing fluorinated solvent was added (second stage). Next, $25 \mathrm{~mL}$ of the aqueous solution after the second extraction was separated, and $25 \mathrm{~mL}$ of a fresh D2EHPA-containing fluorinated solvent was added (third stage). Finally, the third treated aqueous solution was separated and the cesium concentration of the aqueous solution of each stage was measured. The experiment was performed under two $\mathrm{pH}$ conditions; one in which the $\mathrm{pH}$ of the aqueous phase was readjusted to 13 by adding a $5 \mathrm{~mol} / \mathrm{L} \mathrm{NaOH}$ aqueous solution before extraction and the other one in which the $\mathrm{pH}$ of the aqueous phase was not readjusted (control).
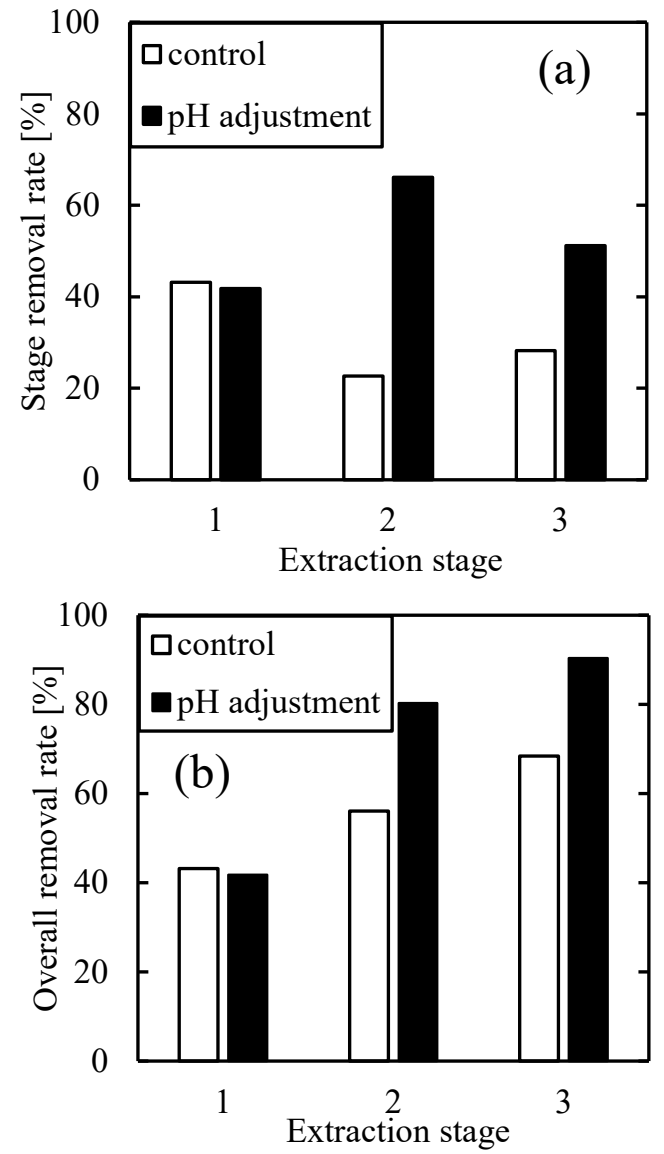

Figure 4. Cesium removal results during multiple extraction (HCFC-225): (a) Stage removal rete; (b) Overall removal rate 
In the case of using HCFC-225, the cesium removal rate lowered in the second and third stages when there was no $\mathrm{pH}$ adjustment of the aqueous cesium solution after the first extraction as shown in Figure 4(a). This is because the $\mathrm{pH}$ of the aqueous solution was lowered by the first stage extraction. The aqueous-phase $\mathrm{pH}$ changed from 13 to 6.1 after the first stage extraction. On the other hand, under the condition of $\mathrm{pH}$ readjustment, the removal rate of about $60 \%$ was maintained in the second and subsequent extractions because the proton concentration was lowered by the addition of the aqueous sodium hydroxide solution. The reason why the removal rate of the first stage is lower than that of the second and third stages is considered to be that the contact between the two phases is insufficient due to a large amount of liquid.

As shown in Figure 4(b), the overall cesium removal rate in multiple extraction tests exceeded $90 \%$. An improvement in removal rate could be achieved.
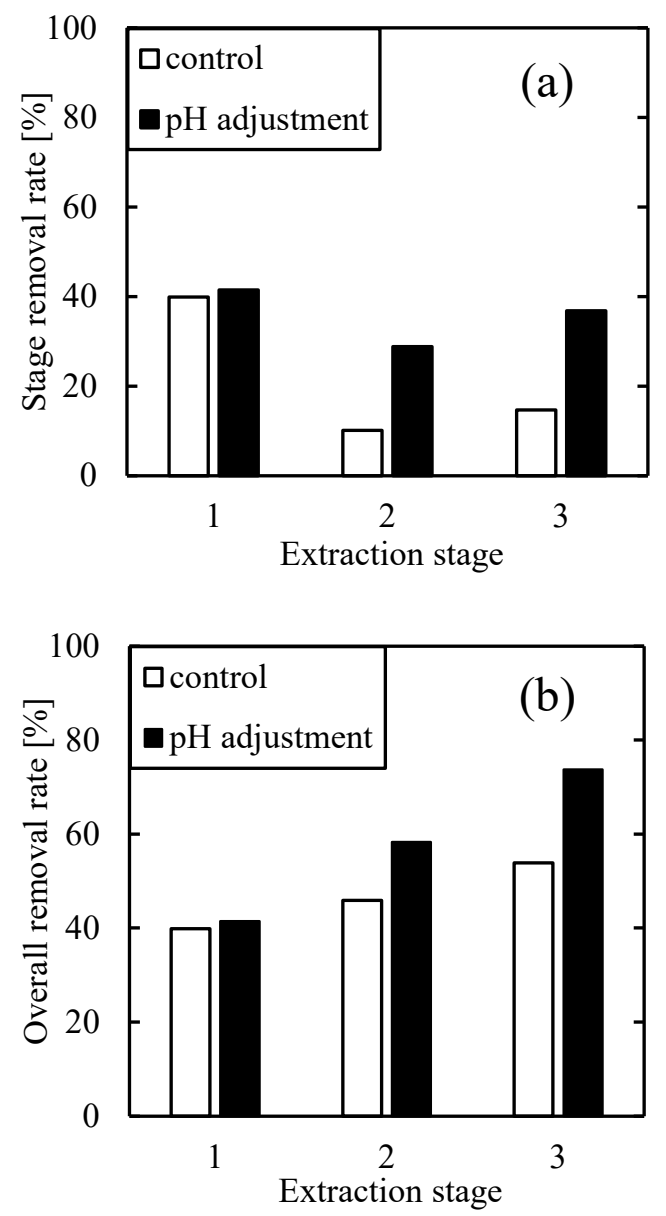

Figure 5. Cesium removal results during multiple extraction (HFE-347-pc-f): (a) Stage removal rete; (b): Overall removal rate

The same tendency was observed in HFE-347-pc-f as shown in Figure 5. The aqueous-phase $\mathrm{pH}$ changed from 13 to 5.4 after first stage extraction. However, because hydrofluoroether has lower solubility of hydrocarbon oil compared with hydrochlorofluorocarbon (Sekiya and Misaki, 2000), the cesium removal rate in HFE-347-pc-f was lower than that in HCFC-225. Furthermore, HFE-347-pc-f had a strong tendency to gelate, especially in the second and subsequent stages. As a result, it took more time for phase separation. It is necessary to consider an effective method to eliminate gelation when operating the device.

\subsection{Flow type device}

Cesium extraction was performed using the flow type device. Table 2 summarized the cesium removal results. The removal rate was the same level as that in the batch system. Even if the total flow rate was changed and the residence time in the mixing section was shortened, the removal rate was almost maintained. The result implies that the cesium aqueous solution can be treated in a short time.

Even when HFE-347-pc-f was used, the removal rate was also the same level as that in the batch system.

Table 2. Cesium removal results by flow type device

\begin{tabular}{cccc}
\hline Solvents & $\begin{array}{c}\text { Total } \\
\text { flow rate } \\
{[\mathrm{ml} / \mathrm{min}]}\end{array}$ & $\begin{array}{c}\text { Residence } \\
\text { time in } \\
\text { mixing } \\
\text { section } \\
{[\mathrm{s}]}\end{array}$ & $\begin{array}{c}\text { Removal rate } \\
{[\%]}\end{array}$ \\
\hline HCFC-225 & 8 & 13.3 & $61.9 \pm 0.43$ \\
HCFC-225 & 32 & 2.8 & $60.5 \pm 0.93$ \\
HCFC-225 & 52 & 2.0 & $61.1 \pm 0.56$ \\
HFE-347-pc-f & 50 & 2.1 & $50.5 \pm 0.01$ \\
\hline Conditions: initial $\mathrm{pH}=13,[\mathrm{D} 2 \mathrm{EHPA}]=0.15 \mathrm{~mol} / \mathrm{L}$
\end{tabular}

\section{Conclusion}

The extraction of cesium ion was performed by D2EHPA with fluorinated solvents. Extraction with a fluorinated solvent showed a removal rate of 50 to $60 \%$ and higher removal performance than that with cyclohexane. The most suitable condition for cesium extraction was $\mathrm{pH}=13$ and $[\mathrm{D} 2 \mathrm{EHPA}]=0.15 \mathrm{~mol} / \mathrm{L}$. The cesium ion could be further removed by performing multiple extractions. The same cesium removal performance as the batch system was obtained in the flow type device. The volume reduction of cesiumcontain solvent will be achieved by distilling fluorinated solvent.

\section{Acknowledgements}

This study has been carried out with the support by Nanba Ltd., Japan.

\section{References}

Antico, E., A. Masana, M. Hidalgo, V. Salvado, M. Iglesias, and M. Valiente; "Solvent Extraction of Yttrium from Chloride Media by di(2ethylhexyl)phosphoric Acid in Kerosene. Speciation 
Studies and Gel Formation," Anal. Chim. Acta, 327, 267-276 (1996)

Ibrahim T. H.; "Role of Water Molecules in Sodium bis(2-ethylhexyl) Phosphate Reversed Micelles in $n$ Heptane,” J. Frankl. Inst., 347, 875-881 (2010)

Jang E., Y. Jang, and E. Chung; "Lithium Recovery from Shale Gas Produced Water Using Solvent Extraction," Appl. Geochem., 78, 343-350 (2017)

Mansur M. B., M. J. Slater, and E. C. Biscaia, Jr.; "Equilibrium Analysis of the Reactive Liquid-Liquid Test Systems $\mathrm{ZnSO}_{4} / \mathrm{D} 2 \mathrm{EHPA} / n$-heptane," Hydrometallurgy, 63, 117-126 (2002)

Sekiya, A. and S. Misaki; "The Potential of Hydrofluoroethers to Replace CFCs, HCFCs and PFCs," J. Fluorine Chem., 101, 215-221 (2000) 